\title{
Medico-Legal Forum: The Electronic Medical Record: Legal Issues to Consider Part I: Patient Care or Paper Care or Who Cares?
}

Gilbert I. Martin, MD

Doctors hate to write. Perhaps the accumulation of all those undergraduate courses with small calculus-like equations followed by medical school, where every word seemed so important, set the stage for...poor legibility. The handwriting is terrible...he/she must be a doctor. How many times I have heard this when scribbling a prescription or finishing a progress note. Externs, interns, and residents....as the years progressed, the notes regressed.

"Doctors hate to write. Perhaps the accumulation of all those undergraduate courses with small calcullus-like equations followed by medical school, where every word seemed so important, set the stage for...poor legibility. The handwriting is terrible....he/she must be a doctor."

To simplify matters, checklists and templates were designed, and notes became data-filled and less explanatory. However, the information was recorded, and the "medical record" documented care...or did it?

Care...patient care, a term physicians use in everyday conversation. However, in today's era of "documentation," patient care is becoming paper care. Under the 1996 Health Insurance Portability and Accountability Act (the Kennedy-Kasselbaum law), documentation requirements will be used to justify the payment. (1) According to this law, to justify a 25-minute visit with a patient, an incredible amount of documentation is required. The chief complaint, an extended history (with several elements necessary), a review of systems (a complete inventory), pertinent history, a complete physical examination, data evaluation, and plan must be present. Wait, you say. This is the stuff we learned in medical school. True, true, I answer. But the complexity of the visit and its documentation will determine which "code" should be used for billing. More time will be spent in fulfilling the "paperwork" requirement than in working with the patient.

Picture the following scenario: Your obstetrical colleague admits a patient at 24 weeks gestation with premature rupture of membranes. After she is stabilized, the neonatologist is asked to speak to the family regarding prognosis and also attends the delivery three days later. The baby is intubated, given surfactant, and placed on a ventilator, and umbilical access is obtained. The neonatologist spends many hours stabilizing this infant during the first 24-hour period. Only five organ systems are described (instead of six) in the written note, with two elements in four systems noted rather than in all systems. Because of this failure of documentation and recording, the auditor changes the code and reduces the corresponding fee. Suddenly the focus is on the paper and not the patient. The art of medicine, the time we can spend with our patients and their families, is being eroded by the necessity of following all of the rules to receive payment.
What is so important about payment? When my toilet fills up, or the washing machine breaks down, I call the plumber. He comes, does his job, and presents a bill, and I pay it. No discounted "plunging" for service. An hourly fee with additions for nighttime and weekend service. I determined long ago that a cash transaction for a plastic fork enmeshed in the garbage disposal is worth six hours of neonatal intensive care, including intubation and umbilical artery catheterization.

Somewhere in history, the reason for writing a medical note has been forgotten because the written record is used for multiple reasons. We were taught that the information documented in the chart would assist all members of the "health team" in caring for the patient. We have lost sight of our 'purpose' and should inform our legal colleagues that there is a difference between completeness and obfuscation.

In today's world, most hospital notes are electronic. The electronic medical record (EMR) enables the healthcare professional to see more patients. But reviewing the EMR from a medical-legal standpoint has many pluses as well as minuses. The EMR often does not present information in a meaningful way so that the reader will understand what is happening to the patient and especially the plan. Fast forward to a medical malpractice scenario where these electronic notes are not clear or meaningful.

"In today's world, most hospital notes are electronic. The electronic medical record (EMR) enables the healthcare professional to see more patients. But reviewing the EMR from a medical-legal standpoint has many pluses as well as minuses. The EMR often does not present information in a meaningful way so that the reader will understand what is happening to the patient and especially the plan."

Part II of this series will discuss the benefits and shortcomings of the electronic medical record and how the author must be aware of the medical-legal consequences.

\section{References:}

1. House of Representatives, Congress. (1996, July 30). $H$. Rept. 104-736 - HEALTH INSURANCE PORTABILITY AND ACCOUNTABILITY ACT OF 1996. [Government]. U.S. Government Publishing Office. https://www.govinfo.gov/app/details/CRPT-104hrpt736/CRPT-104hrpt736.

Disclosure: There are no reported conflicts.

NT 


\section{Corresponding Author}

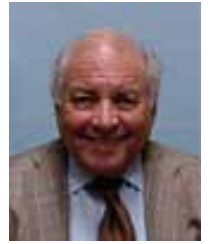

Gilbert I Martin, MD, FAAP

Division of Neonatal Medicine

Department of Pediatrics

Professor of Pediatrics

Loma Linda University School of Medicine

Email: gimartin@llu.edu

Office Phone: 909-558-7448
TAKE THE NECESSARY STEPS TO

\section{ELIMINATE INEQUITIES}

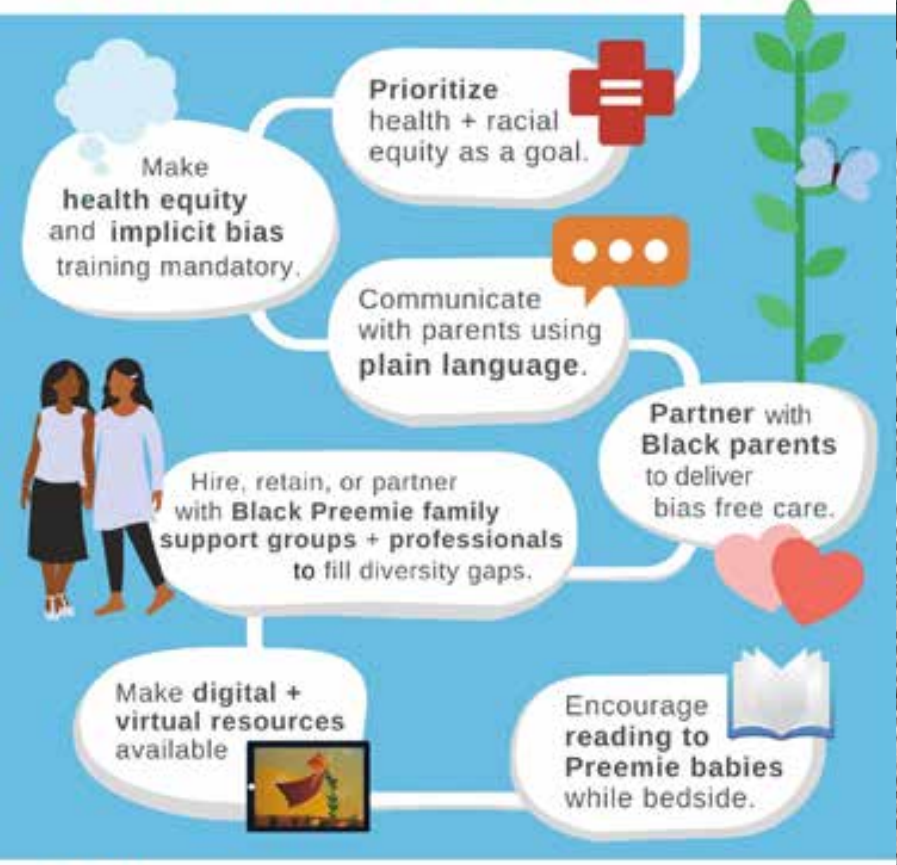

QU AP

ONCEUPONAPREEMIEACADEMY.COM O2020 BY ONCE UPON A PREEMIE ACADEMY.

\section{Oo National Perinatal Association PERINATAL MENTAL HEALTH}

nationalperinatal.org/position

www.nationalperinatal.org/mental_health

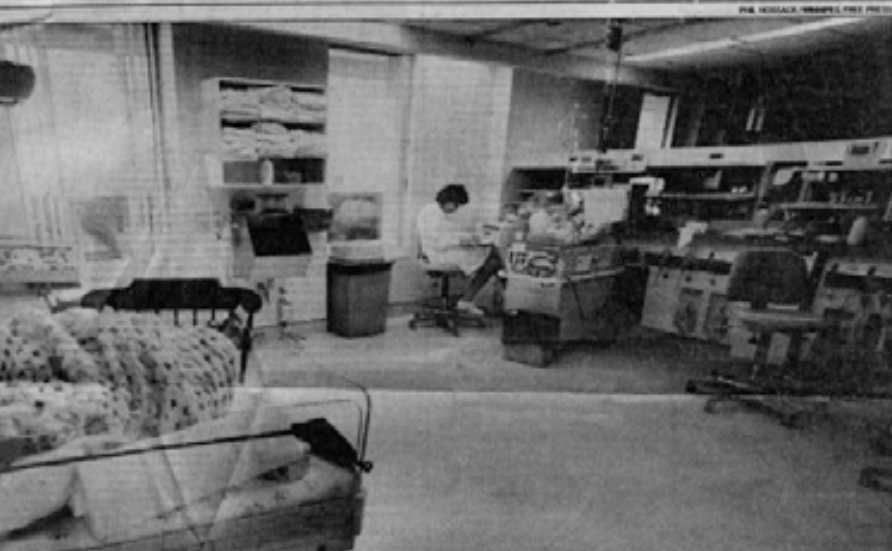

Educate. Advocate. Integrate.

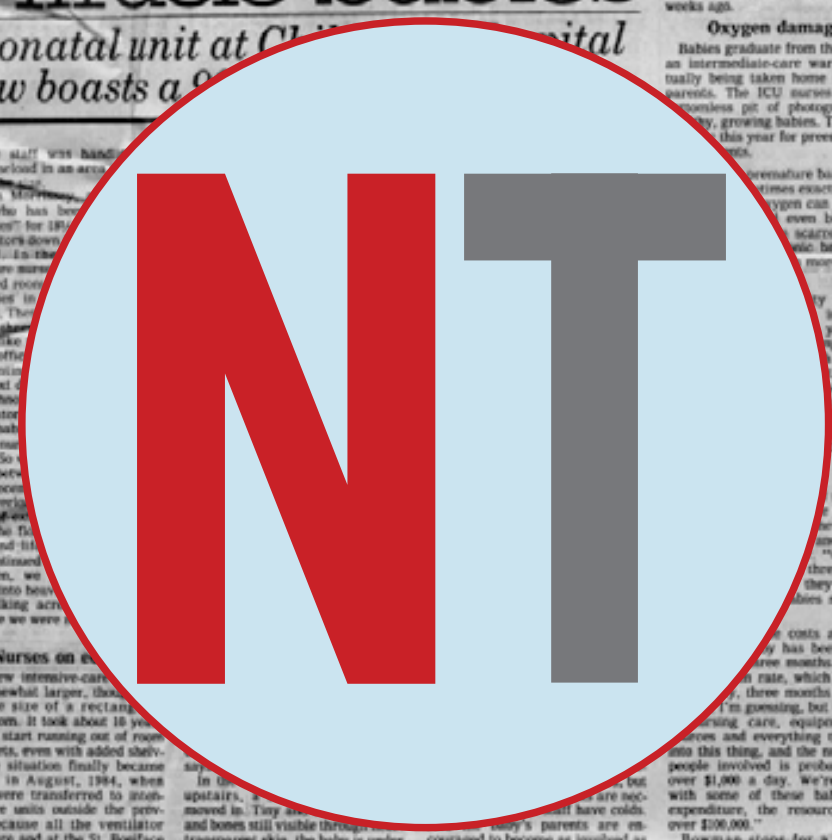

Sign up for free membership at 99nicu, the Internet community for professionals in neonatal medicine. Discussion Forums, Image Library, Virtual NICU, and more..." 